\title{
STUDI TENTANG SIFAT FISIS KAYU LAPIS BERMUKA POLIURETAN
}

\author{
Achmad Supriadi*dan M. I. Iskandar \\ Pusat Penelitian dan Pengembangan Hasil Hutan \\ Jl. Gunung Batu No. 5, Bogor 16610 \\ *e-mail : susupriadi@gmail.com
}

\begin{abstract}
Study on Physical Properties of Polyurethane-faced Plywood

Polyurethane plywood include one of the products of secondary plywood that does not use adhesive coating. Giving a polyurethane coating can be a surface or both surfaces intended that plywood is more beautiful and more durable. The study aimed to examine the physical properties of the polyurethane-faced plywood from three companies. The results showed an average quality appearance included in A level. dimension covered an average thickness of $3.0 \mathrm{~mm}$, a length of 2,440 mm, a width of $1220.2 \mathrm{~mm}$ and 2727.5 $\mathrm{mm}$ in diagonal, the water content of $10.25 \%$ and delamination of $10 \mathrm{~mm}$. All the plywood of faced polyurethane material had resistance to acids, bases and diluent. All parameters of the physical properties of the polyurethane-faced plywood met the standards of buyers from Japan. Statistically there was no significant effect on the physical properties of the original material plywood of faced polyurethane. Polyurethane coated adhesive ability of polywood as the result of this research explained why the adhesive had been used extensively in composite wood products such as plywood.
\end{abstract}

Keywords: Plywood polyurethane, quality appearance, physical properties, standard

\begin{abstract}
ABSTRAK
Kayu lapis bermuka poliuretan termasuk salah satu produk dari kayu lapis sekunder yang tidak menggunakan pelaburan perekat. Pemberian lapisan poliuretan bisa satu permukaan atau kedua permukaannya bertujuan agar kayu lapis lebih indah dan lebih tahan lama. Studi ini bertujuan untuk mencermati sifat fisis kayu lapis bermuka poliuretan yang berasal dari tiga perusahaan penghasil kayu lapis bermuka poliuretan. Hasil penelitian menunjukkan rata-rata mutu penampilan termasuk A. dimensi meliputi rata-rata tebal 3,0 $\mathrm{mm}$, panjang $2.440 \mathrm{~mm}$, lebar 1.220,2 $\mathrm{mm}$ dan diagonal 2.727,5 mm. Kadar air 10,25\% dan delaminasi $10 \mathrm{~mm}$. Semua bahan kayu lapis bermuka poliuretan memiliki ketahanan terhadap asam, basa dan pengencer. Semua parameter sifat fisis kayu lapis bermuka poliuretan memenuhi standar pembeli dari Jepang. Secara statistik tidak ada pengaruh nyata asal bahan terhadap sifat fisis kayu lapis bermuka poliuretan. Kemampuan perekat poliuretan untuk pelapis sebagaimana ditunjukkan dari hasil pencermatan ini ikut menjelaskan mengapa perekat ini telah digunakan luas pada produk komposit kayu termasuk kayu lapis.
\end{abstract}

Kata kunci : Kayu lapis bermuka poliuretan, mutu penampilan, sifat fisis, standar

\section{PENDAHULUAN}

Industri kayu termasuk industri kayu lapis merupakan industri kehutanan yang penting dalam rangka pemanfaatan sumberdaya hutan. Nilai ekspor industri kayu pada tahun 2009 sebesar US \$ 768.000.000 atau 43,18\% dari nilai ekspor hasil pertanian dan kehutanan atau 9,75\% dari seluruh nilai ekspor (Anonim, 2010). Industri kayu penghasil devisa tersebut antara lain kayu lapis penggunaan umum, kayu lapis bermuka poliuretan, kayu olahan, pulp, kom-ponen mebel, dan mebel.
Kayu lapis semula merupakan hasil perekatan beberapa lembar venir dengan arah serat saling bersilangan tegak lurus, kemudian berkembang dengan menggunakan bahan lain sebagai lapisan inti (tengah), sedangkan lapisan luarnya tetap venir dan susunannya tetap bersilangan tegak lurus. Berdasarkan tingkat pengolahan, kayu lapis dibeda-kan menjadi tiga tingkat pengolahan yaitu kayu lapis pengolahan primer, kayu lapis pengolahan sekunder dan kayu lapis pengolahan tersier. Pada pengolahan primer, dolok dibuat venir 
kemudian direkat menjadi kayu lapis, termasuk intinyayang bukan venir. Pada pengolahan sekunder, kayu lapis hasil pengolahan primer pada bagian terluarnya diberi lapisan lain agar lebih indah dan lebih tahan lama. Pemberian bahan pelapis ada yang menggunakan perekat dan ada yang tidak menggunakan perekat. Kayu lapis sekunder yang menggunakan perekat yaitu kayu lapis indah, kayu lapis bermuka kertas dan kayu lapis bermuka polivinil klorida. Kayu lapis sekunder yang tidak menggunakan pelaburan perekat yaitu kayu lapis bermuka kertas fenol, kayu lapis bermuka kertas melamin, kayu lapis bermuka cat, kayu lapis bermuka poliuretan dan kayu lapis bermuka bahan pewarna. Pada pengolahan kayu lapis tersier, kayu lapis pengolahan primer atau sekunder diolah lagi menjadi barang setengah jadi atau barang jadi, misalnya komponen mebel dan parket (Sutigno et al., 2010)

Beberapa kebijakan pemerintah telah mendorong perkembangan industri kayu. Sebagai contoh, dapat dikemukakan bahwa mulai tahun 1985 ekspor kayu bundar dilarang, sehingga ekspor hasil olahan kayu seperti kayu lapis, kayu gergajian untuk pulp, komponen mebel dan mebel meningkat cukup pesat. Pada tahun 1989 diterbitkan peraturan mengenai kenaikan pajak ekspor kayu gergajian sehingga mulai tahun 1990 ekspor kayu gergajian turun sekali tetapi ekspor kayu olahan dan produk kayu lapis terus meningkat.

Disamping terjadi peningkatan jumlah industri juga terjadi peningkatan keaneka-ragaman (diversifikasi) produk industri hasil pengolahan baik secara horizontal maupun vertikal atau pengolahan yang lebih hilir (Sutigno, 2006). Sebagai contoh terkait dapat dikemukakan bahwa semula produk kayu lapis bermuka poliuretan belum berkembang di Indonesia, kini produk tersebut telah berkembang dan telah di ekspor.

Poliuretan merupakan polimer hasil reaksi berantai antara isosianat dengan alkohol. Poliuretan sebelum mengeras (curing) bertekstur lunak, sehingga dapat digunakan sebagai perekat/pelapis. Setelah curing atau reaksi berantai tersebut secara lurus atau secara silang (cross-link) menjadi intensif, poliuretan akan mengeras dan tidak bisa kembali lagi menjadi lunak meskipun ada perubahan suhu atau kondisi lain di sekitarnya. Oleh sebab itu, poliuretan termasuk perekat thermosetting. Sifat ini menyebabkan perekat poliuretan menghasilkan ikatan kuat antara perekatsubstrat (gaya adesi) dan perekat-perekat (gaya kohesi), yang tahan terhadap perubahan kondisi lingkungannya (Ebnesajjad, 2008; Anonim 2011, 2012). Pada reaksi polimerisasi, poliuretan melepaskan molekul air (kondensasi), dan ini ikut berperan pada sifatnya yang polar. Sifat tersebut mengakibatkan adanya tegangan permukaan pada saat bersentuhan dengan bahan yang akan direkat/dilapis (substrat), sehingga menyebar luas pada permukaannya (adesi). Oleh sebab itu lapisan perekat poliuretan bisa berfungsi secara efektif pada permukaan baik yang tidak porous (kaca, metal) maupun porous (kayu, komposit kayu). Dengan demikian poliuretan banyak digunakan secara luas untuk perekat/pelapis permukaan pada kayu lapis sebagai salah satu produk komposit tersebut (Blomquist et al., 1981; Anonim, 2011).

Sehubungan dengan segala uraian terkait, tulisan ini menyajikan hasil pencermatan sifat fisis kayu lapis bermuka poliuretan, meliputimutu penampilan, dimensi (tebal, panjang, lebar, diagonal), kadar air, delaminasi, ketahanan terhadap asam, ketahanan terhadap basa dan ketahanan terhadap pengencer (tiner).

\section{METODE PENELITIAN}

\section{Lokasi Penelitian}

Pengambilan bahan penelitian berupa kayu lapis pada tiga perusahaan yang terletak di Semarang Jawa Tengah, Tangerang dan Cilegon Banten. Pengujian sifat kayu lapis dilakukan di Laboratorium Produk Majemuk Pusat 
Penelitian dan Pengembangan Hasil Hutan Bogor.

\section{Bahan dan Alat}

Bahan yang digunakan dalam penelitian ini yaitu kayu lapis bermuka poliuretan, sedangkan alat yang digunakan adalah meteran, kaliper, timbangan, oven, gergaji mesin dan penangas.

\section{Metode}

a. Memilih contoh uji sebanyak 5 lembar kayu lapis bermuka poliuretan (dari setiap pabrik kayu lapis), lalu dibuat ukurannya menjadi panjang $1220 \mathrm{~mm}$ dan lebar $300 \mathrm{~mm}$. Dari setiap lembar kayu lapis tersebut, disiapkan (dibuat) potongan uji sebanyak 5 buah berukuran $30 \mathrm{~cm} \times 30 \mathrm{~cm}$, dengan pola mengikuti prosedur (Anonim, 2009), seperti disajikan pada Gambar 1. Potongan uji tersebut dianggap sebagai ulangan (lima kali) pada tahapan pengujian berikut.

b. Melakukan pengujian visual meliputi mutu penampilan dan dimen- si (panjang, lebar, tebal dan diagonal).

c. Melakukan pengujian sifat produk kayu lapis bermuka poliuretan, yaitu meliputi kadar air, delaminasi, ketahanan ter-hadap asam, ketahanan terhadap basa dan ketahanan terhadap pengencer (tiner).

\section{Analisis Data}

Data hasil pengujian dimensi(tebal, panjang, lebar, diagonal), kadar air, delaminasi, ketahanan terhadap asam, ketahanan terhadap basa dan ketahanan terhadap pengencer kayu lapis bermuka poliuretan dihitung rata-ratanya kemudian dibandingkan dengan standar yang digunakan. Untuk mengetahui pengaruh asal bahan (dari 3 pabrik) terhadap sifat fisis kayu lapis poliuretan dilakukan analisis sidik ragam. Banyaknya ulangan 5 buah (conto huji). Sekiranya pengaruh asal bahan (pabrik pembuat kayu lapis) nyata terhadap sifat fisis kayu lapis bermuka poliuretan, penelaahan dilanjutkan dengan uji beda jarak nyata jujur (BNJ). Pengolahan data dilakukan dengan bantuan program Minitab (Hendradi, 2006).

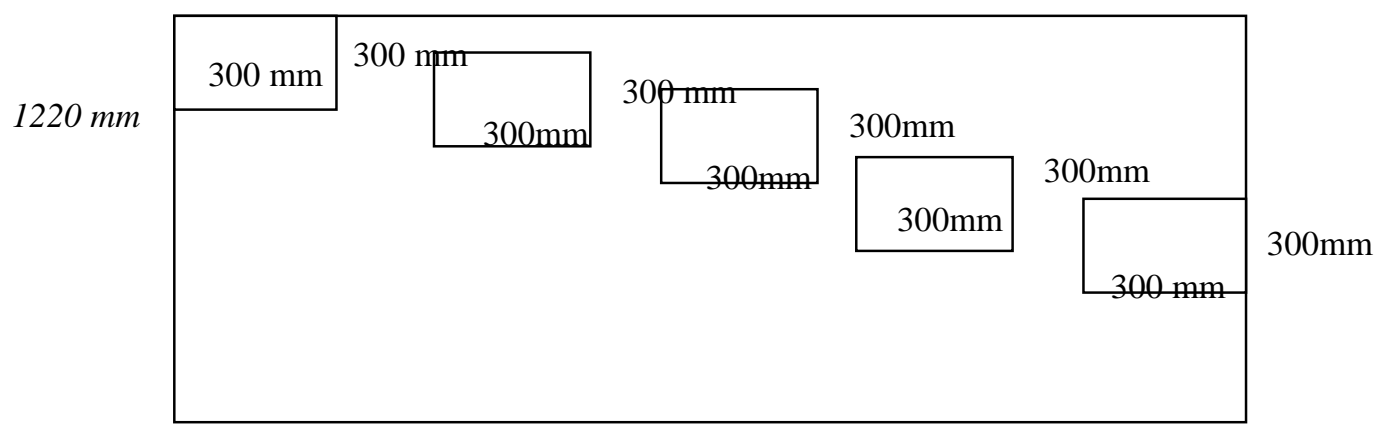

Gambar 1. Pola potongan uji kayu lapis bermuka poliuretan 
HASIL DAN PEMBAHASAN

Hasil pengujian mutu penampilan, dimensi (tebal, panjang, lebar, diagonal), kadar air, delaminasi, ketahanan terhadap asam, ketahanan terhadap basa, dan ketahanan terhadap pengencer kayu lapis bermuka poliuretandisajikan pada Tabel 1. Untuk mengetahui pengaruh asal bahan terhadap sifat fisis kayu lapis poliuretan dilakukan analisis keragaman dan hasilnya disajikan pada Tabel 2 .

Tabel 1. Sifat Fisis Kayu Lapis Bermuka Poliuretan*)

\begin{tabular}{|c|c|c|c|c|c|}
\hline \multirow{2}{*}{ No. } & \multirow{2}{*}{ Parameter fisis } & \multicolumn{3}{|c|}{ Asal bahan } & \multirow{2}{*}{ Rata-rata } \\
\hline & & A & B & $\mathrm{C}$ & \\
\hline 1 & Mutu penampilan & "A" & "A" & "A" & "A" \\
\hline 2 & Tebal,mm & 3,0 & 3,0 & 3,0 & 3,0 \\
\hline 3 & Panjang, mm & 2.440 & 2.440 & 2.440 & 2.440 \\
\hline 4 & Lebar, mm & 1.220 & $1.220,4$ & $1.220,3$ & $1.220,2$ \\
\hline 5 & Diagonal, mm & $2.727,0$ & $2.728,0$ & $2.727,4$ & $2.727,5$ \\
\hline 6 & Kadar air, \% & 10.40 & 10.40 & 9,95 & 10,25 \\
\hline 7 & Delaminasi, mm & 12,0 & 9,0 & 9,0 & 10 \\
\hline 8 & Ketahanan terhadap asam & \multicolumn{4}{|c|}{$\begin{array}{l}\text { Tidak ada yang mengelupas, melepuh, } \\
\text { pecah dan pelunakan }\end{array}$} \\
\hline 9 & Ketahanan terhadap basa & \multicolumn{4}{|c|}{$\begin{array}{l}\text { Tidak ada yang mengelupas, melepuh, } \\
\text { pecah dan pelunakan }\end{array}$} \\
\hline 10 & Ketahanan terhadap pengencer & \multicolumn{4}{|c|}{$\begin{array}{l}\text { Tidak ada yang mengelupas, melepuh, } \\
\text { pecah dan pelunakan }\end{array}$} \\
\hline
\end{tabular}

*) Keterangan: Rata-rata dari 5 ulangan;

A, B, C menunjukkan asal pabrik kayu lapis.

Tabel 2. Analisis Keragaman Pengaruh Asal Bahan Terhadap Fisis Kayu Lapis Bermuka Poliuretan

\begin{tabular}{llccc}
\hline No. & \multicolumn{1}{c}{ Parameter fisis } & db & Kuadrat tengah & F hitung \\
\hline 1 & Lebar (mm) & 2 & 1,067 & $1,68 \mathrm{tn}$ \\
& Asalbahan & 12 & 0,633 & \\
& Galat & & & \\
2 & Diagonal(mm) & 2 & 1,267 & $2,11 \mathrm{tn}$ \\
& Asal bahan & 12 & 0,600 & \\
& Galat & & & $1,03 \mathrm{tn}$ \\
3 & Kadar air (\%) & 2 & 0,554 & \\
& Asal bahan & 12 & 0,538 & $1,06 \mathrm{tn}$ \\
& Galat & & & \\
& Delaminasi (mm) & 2 & 15,0 & \\
& Asal bahan & 12 & 14,2 & \\
$\quad$ Galat & & & \\
\hline tn $=$ tidak nyata (non significant) & & &
\end{tabular}




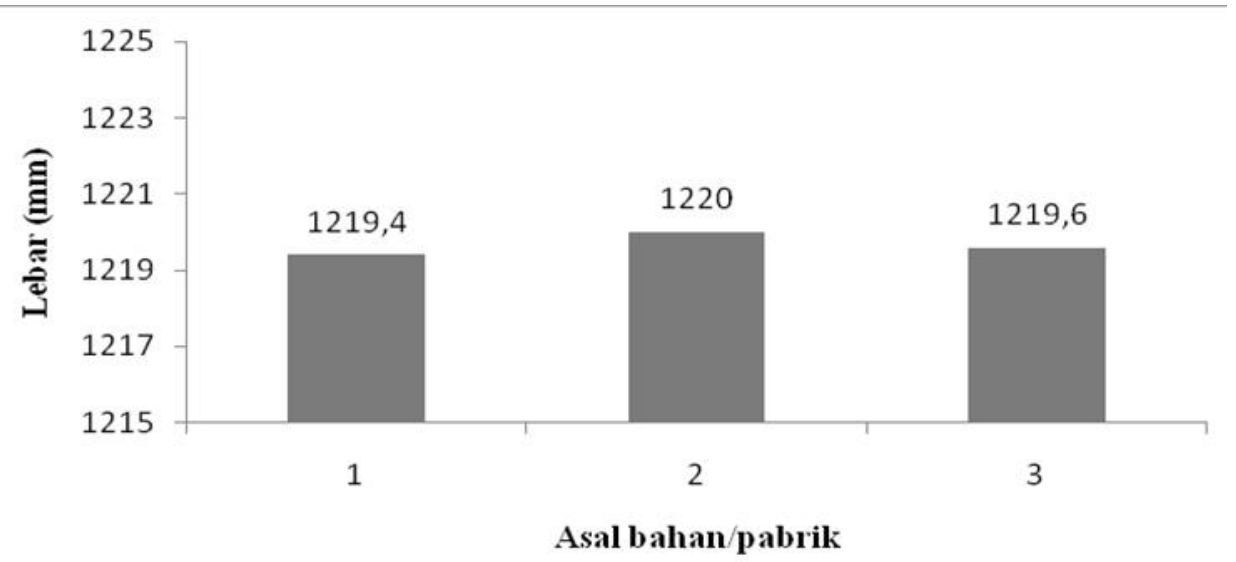

Gambar 2. Lebar Rata-rata Kayu Lapis Bermuka Poliuretan dari 3 Pabrik

Mutu penampilan kayu lapis bermuka poliuretan yang diuji termasuk mutu A menurut standar pembeli dari Jepang, karena tidak ada cacat pada permukaan kayu lapis bermuka poliuretan seperti perubahan warna, noda jamur, potongan kasar, noda perekat, noda minyak, oli dan kapur berwarna, goresan, cacat kempa dan ketebalan tidak rata.

Kayu lapis bermuka poliuretan memiliki rata-rata tebal 3,0 $\mathrm{mm}$, panjang $2.440 \mathrm{~mm}$, lebar $1.220,2 \mathrm{~mm}$ dan panjang diagonal $2.727,5 \mathrm{~mm}$. Nilai dimensi tersebut (Tabel 1) bila dibandingkan dengan standar pembeli dari Jepang, memenuhi persyaratan standar karena terletak dalam toleransi standar yaitu $\pm 0.2 \mathrm{~mm}$ untuk tebal, $\pm 2 \mathrm{~mm}$ untuk panjang, $(-0 \mathrm{~mm}) \mathrm{s} / \mathrm{d}(+1,5 \mathrm{~mm})$ untuk lebar dan $\leq 3 \mathrm{~mm}$ untuk selisih antara panjang diagonal terpanjang dengan panjang diagonal terpendek. Nilai ini banyak menunjukkan kesamaan bila dibandingkan dengan hasil pengujian kayu lapis bermuka poliuretan yang dilakukan oleh Taufik (2011), Darman (2011) dan Bambang (2011) dan juga memenuhi syarat standar pembeli dari Jepang. Secara statitistik asal bahan tidak berpengaruh nyata terhadap dimensi tebal, panjang, lebar dan diagonal kayu lapis bermuka poliuretan (Tabel 2). Gambar 2 dan Gambar 3 menunjukkan nilai rata-rata lebar dan diagonal kayu lapis bermuka poliuretan yang berasal dari ketiga pabrik.

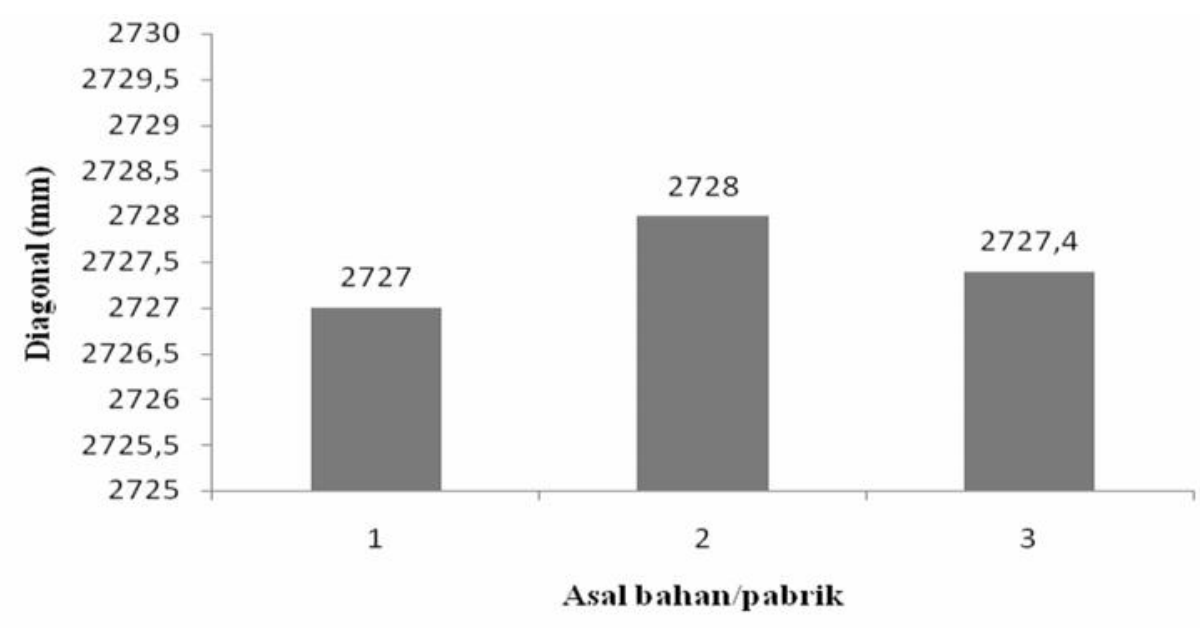

Gambar 3. Diagonal Rata-rata Kayu Lapis Bermuka Poliuretan dari 3 Pabrik 
Kadar air kayu lapis bermuka poliuretan rata-rata $10,25 \%$. Kadar air semua contoh uji memenuhi standar pembeli dari Jepang, karena nilainya kurang dari $14 \%$. Secara statistik perbedaan asal bahan tidak berpengaruh nyata terhadap kadar air kayu lapis bermuka poliuretan (Tabel 2).

Nilai delaminasi kayu lapis bermuka poliuretan rata-rata $10 \mathrm{~mm}$. Semua contoh uji memenuhi standar pembeli dari Jepang, karena nilainya kurang dari $25 \mathrm{~mm}$. Secara statistik asal bahan tidak berpengaruh nyata terhadap delaminasi kayu lapis bermuka poliuretan (Tabel 2). Gambar 4 dan 5 menunjukkan nilai ratarata kadar air dan delaminasi kayu lapis bermuka poliuretan

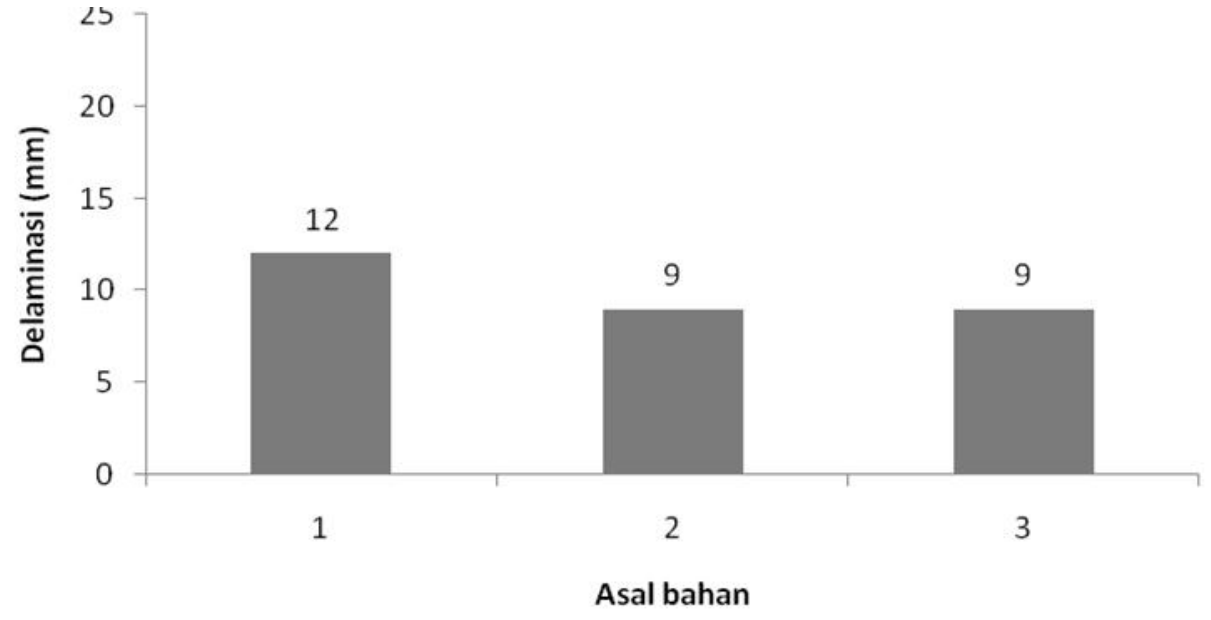

Gambar 4. Nilai Rata-rata Delaminasi Kayu Lapis Bermuka Poliuretan dari 3 Pabrik

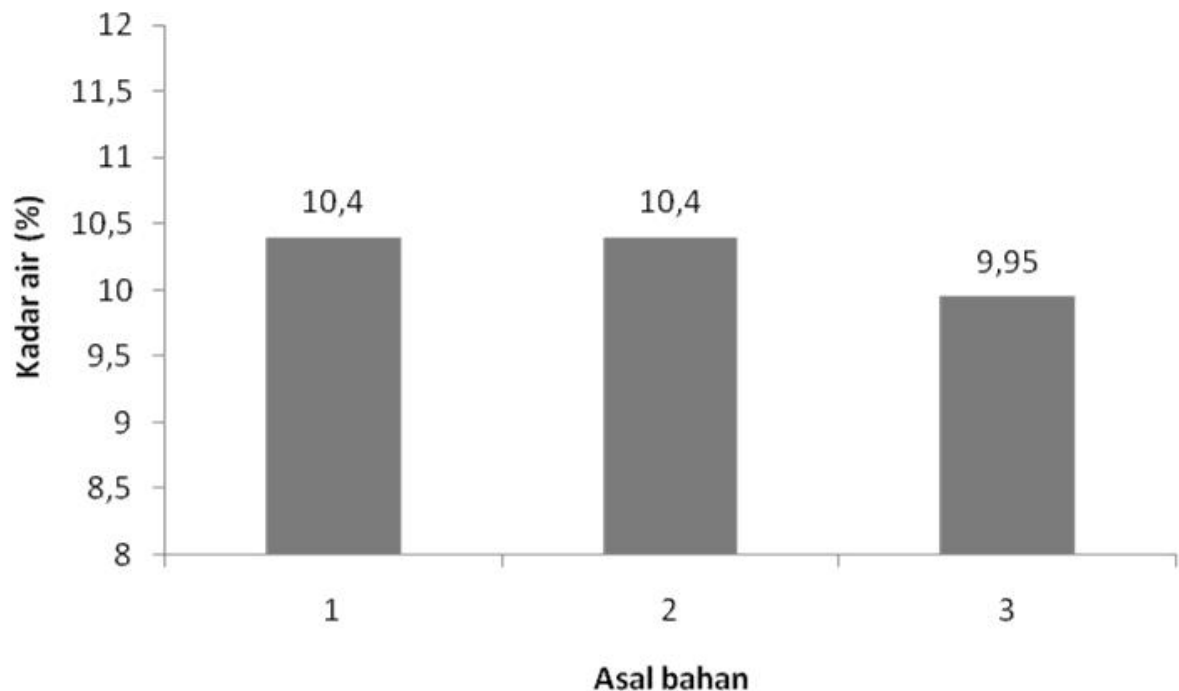

Gambar 5. Nilai Rata-Rata Kadar Air Kayu Lapis Bermuka Poliuretan dari 3 Pabrik 
Hasil pengujian ketahanan terhadap asam, ketahanan terhadap basa dan ketahanan terhadap pengencer kayu lapis bermuka poliuretan semuanya memenuhi syarat karena tidak ada contoh uji yang mengelupas, melepuh, pecah dan mengalami pelunakan. Hasil ini bila dibandingkan dengan hasil pengujian kayu lapis bermuka poliuretan yang dilakukan olehTaufik (2011), Darman (2011) dan Bambang (2011) hasilnya banyak menunjukkan kesamaan dan sama-sama memenuhi syarat standar pembeli dari Jepang

\section{KESIMPULAN}

1. Kayu lapis bermuka poliuretan bermutu penampilan "A", memiliki dimensi rata-rata yaitu tebal $3,0 \mathrm{~mm}$, panjang $2.440 \mathrm{~mm}$, lebar $1.220,2 \mathrm{~mm}$ dan diagonal 2.727,5 mm. Kadar air $10,25 \%$ dan delaminasi $10 \mathrm{~mm}$. Semua bahan kayu lapis bermuka poliuretan memiliki ketahanan terhadap asam, basa dan pengencer

2. Semua parameter sifat fisis kayu lapis bermuka poliuretan memenuhi standar pembeli dari Jepang

3. Tidak ada pengaruh nyata asal bahan/pabrik terhadap sifat fisis kayu lapis bermuka poliuretan.

4. Kemampuan perekat poliuretan yang ditunjukkan dari hasil pencermatan ini ikut menjelaskan telah digunakannya sebagai perekat/ pelapis permukaan secara luas pada produk komposit kayu, termasuk kayu lapis.

\section{DAFTAR PUSTAKA}

Bambang. 2011. Pengujian Kayu Lapis Bermuka Poliuretan. Semarang: PT. Kayu Lapis Indonesia.

Cara Pengujian Kayu Lapis Bermuka Poliuretan. 2009. Cara Pengujian Kayu Lapis Bermuka Poliuretan. Jakarta: PT. Perfecta Nusa.
Blomquist,R.F., A.W. Christiansen, and R.H. Gilespie. 1981. Adhesive bonding of wood and other structural materials. Forest Products Laboratory, Forest Service. USA: USDA Incooperation With the University of Wisconsin. The Pensylvania State University. University Part, PA.

Darman. 2011. Kayu Lapis Bermuka Poliuretan. Serang: PT. Satya Raya Indah Wood Industries (PT. SRIWI.

Departemen Perdagangan. 2010. Laporan Ekspor Produk Kayu. Jakarta:Departemen Perdagangan

Ebnesajjad, E. 2008. Adhesive Technology Handbook. 2nd ed. NY. USA: William Andrew. Norwich.

Hendradi, T.C. 2006. Statistik Six Sigma dengan Minitab. Panduan Cerdas Inisiatif Kualitas. Yogyakarta: ANDI OFFSET.

IM. Sulastiningsih dan M.I.Iskandar. 2010. Proses Pembuatan Kayu Lapis. Bogor: Pusat Penelitian dan Pengembangan Hasil Hutan.

Sutigno, P. 2006. Pengembangan Teknologi Hasil Hutan. Yogyakarta: Buletin Fakultas Kehutanan Universitas Gadjah Mada.

Taufik. 2011. Hasil Uji Kayu Lapis Bermuka Poliuretan. Tangerang: PT. Perpekta Nusa.

Wikipedia. 2011. http:/ cn.Wikipedia .org/Wiki/Polyurethane. Diakses : tanggal 25 Juni 2012.

Wisegeek. 2012. What is polyurethane adhesive?. http://www. Wisegeek .com/what is polyurethane adhesive. httm. Diakses : tanggal 25 Juni 2012. 